\title{
Dual-route tranexamic acid to reduce blood loss in coronary artery bypass graft surgery: a randomized controlled trial
}

\author{
Oksana Prokopchuk-Gauk, MD • Mark W. Rosin, MPS • Taras R. Mycyk, MD • \\ Hyun J. Lim, PhD $\cdot$ Kelsey Brose, MD
}

Received: 2 February 2016/Accepted: 10 June 2016/Published online: 22 June 2016

(c) Canadian Anesthesiologists' Society 2016

\section{To the Editor,}

A 2009 systematic review and meta-analysis ${ }^{1}$ suggested that topical anti-fibrinolytic agents can reduce postoperative bleeding and transfusion requirements in patients undergoing on-pump cardiac surgery. Systemic administration of lysine analogues, including tranexamic acid (TXA), has become the standard of care in patients undergoing on-pump coronary artery bypass graft (CABG) surgery to diminish perioperative blood loss and transfusion requirements. ${ }^{2}$ Here, we report the findings of a double-blind, randomized trial in low-risk CABG surgical patients that evaluated whether co-administration of intravenous and topical TXA has a significant impact on blood loss and transfusion requirements. Approval from

O. Prokopchuk-Gauk, MD

Department of Pathology and Laboratory Medicine, University of Saskatchewan, Saskatoon, SK, Canada

O. Prokopchuk-Gauk, MD - T. R. Mycyk, MD - K. Brose, MD Royal University Hospital, Saskatoon, SK, Canada

M. W. Rosin, MPS

Clinical Perfusion, Royal University Hospital, Saskatoon, SK, Canada

T. R. Mycyk, MD

Division of Cardiac Surgery, Department of Surgery, University of Saskatchewan, Saskatoon, SK, Canada

H. J. Lim, PhD

Department of Community Health and Epidemiology, University of Saskatchewan, Saskatoon, SK, Canada

K. Brose, MD ( $\square)$

Division of Hematology, Department of Medicine, University of Saskatchewan, Saskatoon, SK, Canada

e-mail: kelsey.brose@saskcancer.ca our institutional ethics board was obtained, and written informed consent was given by each participant.

Between December 1, 2011 and April 30, 2012 all patients scheduled for cardiac surgery at our institution were prospectively screened for trial participation. To limit participant heterogeneity, we recruited low-risk surgical candidates defined according to EUROScore criteria ${ }^{3}$ scheduled for elective or urgent CABG.

Our primary outcome was the total volume of postoperative blood loss, determined by measuring mediastinal chest tube drainage. We calculated that a total sample size of 74 participants allowed $80 \%$ power to detect a $200 \mathrm{~mL}$ difference in total blood loss (type I error of 0.05) between groups. Secondary outcomes included chest tube losses at six and $12 \mathrm{hr}$, postoperative red blood cell transfusion requirement, and length of intensive care unit (ICU) stay. Adverse events of a thrombotic nature were recorded.

Participants were randomized to receive an intraoperative topical TXA solution (study arm) or normal saline (control arm) prepared by our institutional clinical trials pharmacy according to a non-blocked randomization list generated before patient enrollment began.

After general anesthesia, but prior to initiation of cardiopulmonary bypass, the study participants received a single intravenous bolus dose of TXA $30 \mathrm{mg} \cdot \mathrm{kg}^{-1}$ over two minutes. Following removal of retractors and sponges prior to sternotomy closure, participants in the study arm received a cardiac bath of TXA solution containing $2 \mathrm{~g}$ TXA ( $1 \mathrm{~g}$ in $10 \mathrm{~mL}$; Pfizer Canada, Saint-Laurent, QC, Canada) plus $50 \mathrm{~mL}$ of pre-warmed $\left(42^{\circ} \mathrm{C}\right)$ normal saline. The control arm received $70 \mathrm{~mL}$ of pre-warmed normal saline only. This fluid remained within the pericardial cavity during placement of mediastinal chest tubes and chest closure. It was subsequently drained to the intraoperative cell-salvage machine by suction. The chest 
Figure Chest tube drainage over time. Mediastinal chest tubes were removed at a mean (standard deviation) of 19.8 (2.3) $\mathrm{hr}$ in the topical tranexamic acid (TXA) arm and 20.6 (2.9) hr in the control arm

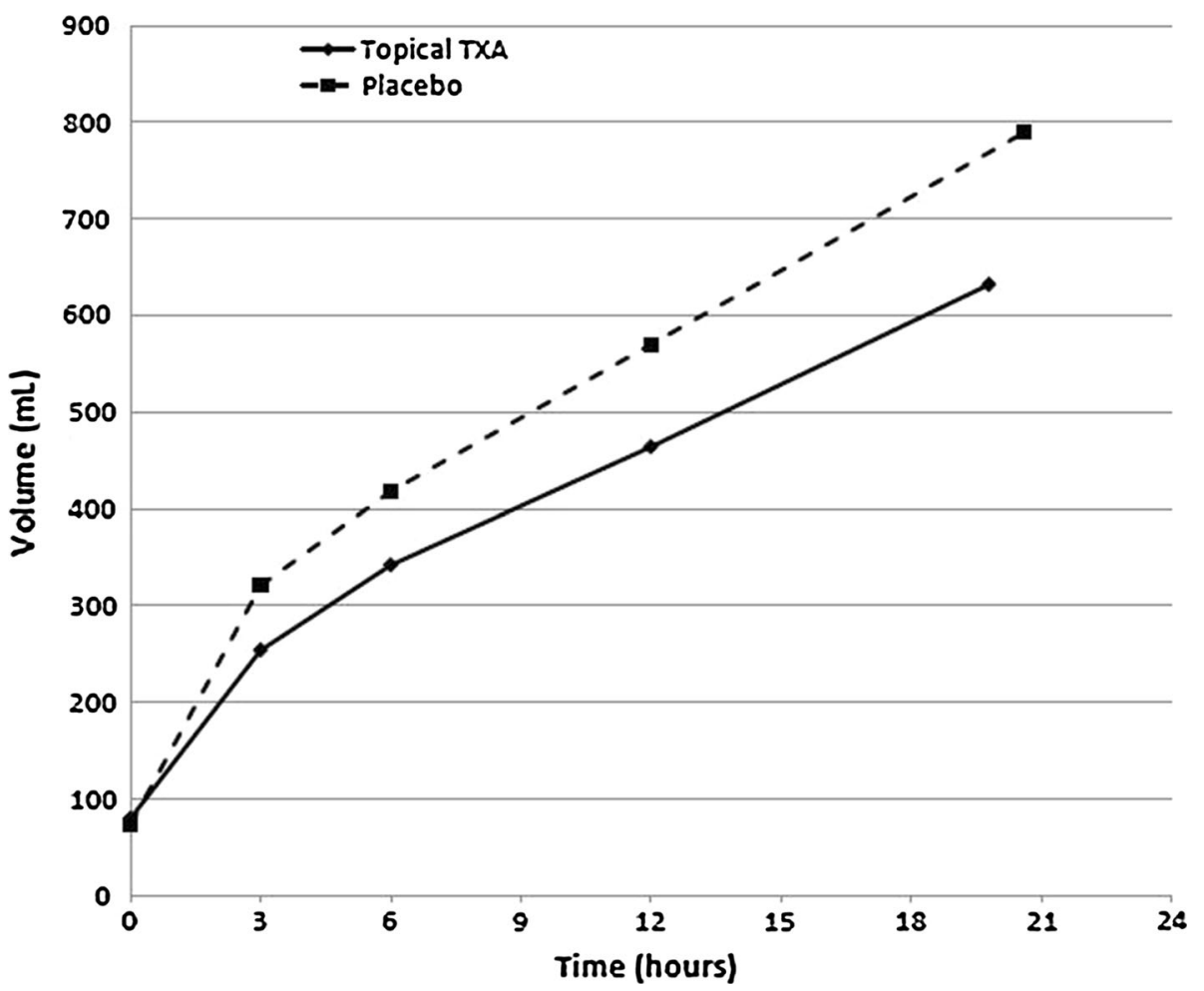

tubes were connected to a portable drainage unit with continuous suction prior to ICU transfer.

The amount of chest tube drainage was recorded by the nursing staff beginning at ICU admission. Chest tubes were removed once the output fell below $200 \mathrm{~mL}$ over six hours.

Overall, 96 of the 149 patients scheduled to undergo cardiac surgery during our study were not eligible. The remaining 41 patients, randomized to the topical TXA arm $(n=23)$ or the control arm $(n=18)$, were included in the final analysis (recruitment into this trial stopped early because of resource constraints). There were no differences in baseline characteristics.

The mean (SD) postoperative chest tube loss at removal (Figure) was 632 (265) $\mathrm{mL}$ in the topical TXA arm vs 789 (216) $\mathrm{mL}$ in the control arm, with a difference of $157 \mathrm{~mL}$ (95\% confidence interval, 0.5 to $312 ; P=0.049$ ). Differences in chest tube drainage were not significant at any other time points. No patients required postoperative red blood cell transfusion. The mean (SD) length of the patients' ICU stay was 24.7 (6.1) hr in the study arm and 24.4 (2.7) $\mathrm{hr}$ in the control arm. No significant adverse outcomes were reported.

The primary limitation of our study was its small sample size, which leads to the possibility that our results were due to chance. However, a recent retrospective study ${ }^{4}$ with a similar study population also suggested that combined-modality TXA administration may be a superior blood conservation strategy. At our institution, we continue to utilize dual-route TXA administration in patients undergoing CABG surgery.
Acknowledgements We thank the Saskatoon Health Region, Health Records Department and Division of Cardiac Surgery for their support and cooperation. We are grateful for the grant from the Department of Medicine, University of Saskatchewan to purchase materials. Special thanks go to Dr. Tom Hurst, whose assistance was invaluable in completing this study.

Conflicts of interest None declared.

Editorial responsibility This submission was handled by Dr. Philip M. Jones, Associate Editor, Canadian Journal of Anesthesia.

\section{References}

1. Abrishami A, Chung F, Wong J. Topical application of antifibrinolytic drugs for on-pump cardiac surgery: a systematic review and meta-analysis. Can J Anesth 2009; 56: 202-12.

2. Hillis LD, Smith PK, Anderson JL, et al. 2011 ACCF/AHA Guideline for Coronary Artery Bypass Graft Surgery: a report of the American College of Cardiology Foundation/American Heart Association Task Force on Practice Guidelines. Circulation 2011; 124: e652-735.

3. Roques F, Nashef SA, Michel P, et al. Risk factors and outcome in European cardiac surgery: analysis of the EuroSCORE multinational database of 19030 patients. Eur J Cardiothorac Surg 1999; 15: 816-22.

4. Mahaffey $R$, Wang L, Hamilton A, Phelan $R$, Arellano $R$. A retrospective analysis of blood loss with combined topical and intravenous tranexamic acid after coronary artery bypass graft surgery. J Cardiothorac Vasc Anesth 2013; 27: 18-22. 